Fecha de recepción: marzo 2020 Fecha de aceptación: abril 2020 Versión final: mayo 2020

\section{Migraciones en el diseño de mobiliario con perspectiva histórica. Antigüedad hasta el siglo dieciocho}

Gastón Girod ${ }^{(1)}$, Alejo García de la Cárcova ${ }^{(2)}$

e Inés Petrocchi ${ }^{(3)}$

\begin{abstract}
Resumen: Desde el comienzo de la historia del diseño, un variado universo de materiales, técnicas y tecnologías irán delineando un repertorio objetual. Las influencias, desde la Antigüedad hasta la Edad Moderna, conformarán una red de movimientos migratorios, motivados por intereses económicos en algunos casos, o como consecuencia del contexto político, social y cultural, en otros. El presente trabajo hará un recorrido por dichas migraciones y estudiará su influencia en la formación y la ampliación del canon en Occidente, en muchas oportunidades, con fuerte influencia Oriental.
\end{abstract}

Palabras clave: diseño - industrial - migración - historia - globalización - centro - periferia - canon - institucionalización.

[Resúmenes en inglés y portugués en la página 122]

(1) Arq. Gastón Girod. Arquitecto, especialista en diseño de mobiliario (UBA). Curso de Posgrado en Gestión de la Pyme de la Madera y el Mueble (Univ. Nac. de Gral. Sarmiento). Magister en Gestión del Diseño (UP). Profesor de la Universidad de Palermo en el Área de Diseño de Objetos y Productos de la Facultad de Diseño y Comunicación. Investigador del Ministerio de Ciencia, Tecnología e Innovación Productiva (MINCyT). Editor del libro Diseño de Mobiliario Argentino Actual y Diseño de Mobiliario 04, enfocado en la problemática latinoamericana. Escritor de la columna de diseño de la Revista D\&D.

(2) D.I. Alejo García de la Cárcova. Licenciado en Diseño (UP). Diseñador Industrial (ORT). Carrera de Formación Docente (FADU/UBA). Docente de la Facultad de Arquitectura, Diseño y Urbanismo (UBA), Universidad de Palermo e Instituto de Tecnología ORT. Investigador de la Secretaría de Ciencia y Técnica (UBACyT). Se desempeña en el área de Desarrollo Académico de la Maestría en Gestión del Diseño y Publicaciones Académicas de la Facultad de Diseño y Comunicación de UP. Coordinador de comisiones en el Congreso Latinoamericano de Enseñanza del Diseño y del Coloquio de Investigación y Desarrollo en Diseño Latino.

(3) Lic. Inés Petrocchi. Licenciada en Ciencias Políticas (Universidad Di Tella) y Diseñadora de Mobiliario (Universidad de Palermo). Ayudante de cátedra de la Facultad de Arquitec- 
tura, Diseño y Urbanismo (UBA) y de la Universidad de Palermo en Historia del Diseño Industrial 1 y 2.

\section{Introducción}

El tema de migración y diseño será abordado en el presente ensayo desde el objeto mueble y su desarrollo en Europa y América. No pretende ser una reseña histórica, simplemente analizar aspectos vinculados a la influencia de las diferentes migraciones en países o regiones occidentales como una evidencia de características particulares que se dan en la configuración del mobiliario, en lo formal, técnico y funcional, dando como resultado un objeto de valor histórico, artístico, estético y simbólico.

La elección es arbitraria y posiblemente incompleta, solo intenta aportar al tema desde este enfoque, ya que el mobiliario como objeto acompaña al ser humano a lo largo de su vida, reflejando momentos de su historia y evidenciando rasgos particulares de cada región, como fuente de riqueza cultural y como vínculo con la memoria. Un aporte para conservar, reivindicar y difundir al objeto mueble y su relación con las migraciones, validando su recuerdo como una forma de que se enriquezcan las identidades culturales.

Para entender de qué se trata el tema y el término migración, se expondrán los conceptos definidos por la Organización Internacional para las Migraciones (OIM) y el Instituto Nacional de Estadística y Censos (INDEC) en la Encuesta Complementaria de Migraciones Internacionales (ECMI).

Según datos del INDEC sobre los Antecedentes de ECMI:

La definición de migración que hacen los censos de población representa sólo una parte de los desplazamientos que experimenta la población y se refiere a los desplazamientos con traslado de residencia desde un lugar de origen a un lugar de destino atravesando los límites de una división geográfica o político administrativa.

Por su parte, la Organización Internacional para las Migraciones (OIM) define a un migrante como:

(...) cualquier persona que se desplaza o se ha desplazado a través de una frontera internacional o dentro de un país, fuera de su lugar habitual de residencia independientemente de: 1) su situación jurídica; 2) el carácter voluntario o involuntario del desplazamiento; 3 ) las causas del desplazamiento; o 4) la duración de su estancia.

Desde los inicios de la civilización se evidencia esta característica de tránsito, traslado o migración del ser humano. Sus motivos son diversos, como por ejemplo: en busca de nuevas oportunidades, por trabajo, estudio, razones económicas o familiares, para escapar de 
persecuciones o conflictos bélicos, entre otros. El análisis estará enfocado en segmentos de la población relacionados con oficios, profesiones o gremios, como también en destacados artesanos, artistas, y/o arquitectos.

\section{Antecedentes en la Antigüedad}

El análisis comenzará con una breve mención del mobiliario en las civilizaciones de la Antigüedad donde no se detallarán migraciones puntuales, sino una continuidad en el conocimiento de tipologías, técnicas constructivas y terminaciones superficiales. "Por ejemplo, los objetos que han llegado hasta nosotros procedentes de las antiguas civilizaciones egipcia, griega y romana son una clara evidencia de los asientos contemporáneos" (Yates, King y Bridge, 1999, p. 18).

Gracias a la información obtenida a partir de los descubrimientos de las tumbas egipcias, donde sus objetos se conservaron en buen estado debido al ambiente hermético, se evidencia que poseían avances técnicos y formales que daban respuesta a su universo existencial. Ensambles y detalles constructivos como el eje de rotación para plegar asientos o el puntal (elemento que ligaba estructuralmente en una silla el asiento con el respaldo), como así también elementos decorativos, imitativos y simbólicos, aplicados con técnicas de talla o desde la elección de las maderas o metales, con policromías e incrustaciones de metales o piedras preciosas, que se evidencian en la construcción de taburetes, sillas, mesas y camas de varios tamaños y formas.

En el caso de los griegos, lo que se conoce es a partir de ilustraciones en vasijas o esculturas ya que no se dispone de ejemplares. Se encuentran tipologías similares a las de los egipcios como el taburete plegable y el lecho que se empleaba como sofá y cama. Existen algunos aportes tipológicos, como la silla klismos, las mesas auxiliares de tres patas y el kline o lecho de descanso.

Por su parte, el mobiliario romano:

(...) es derivación directa del griego, si bien a partir de los últimos tiempos de la República exhibe una pasión típicamente romana por el lujo. En la literatura se habla del prodigio empleo de las maderas preciosas y de incrustaciones de los más diversos materiales (oro, plata, cobre, bronce, marfil y carey) (LucieSmith, 1980, p. 28).

Algunos aportes tipológicos romanos son las silla de medio tonel y el lectus, antecedente del futuro sillón. El taburete plegable se convierte en la sella curulis, emblema de la autoridad de los magistrados romanos. Con respecto a los avances técnicos, se puede mencionar el torneado de la madera, la fundición de metal, presente en el trípode de bronce (mesa auxiliar encontrada en las ruinas de Pompeya anterior a 79 DC) y la incorporación de almohadones como un aporte al confort del mueble. "La fabricación de tumbonas griegas y romanas más elegantes, apoyadas sobre delicadas patas, dependía de los expertos y disciplinados artesanos que transmitían sus técnicas a toda Europa” (Yates, King y Bridge, 1999, p. 19). 


\section{Europa en la Edad Media y Moderna}

Muchas de estas técnicas prevalecieron más allá de la denominada Edad Media u Oscura y es posible que el carácter nómade de algunos pobladores fuese un factor que permitió el intercambio de información sobre cuestiones tipológicas, formales y técnicas, junto con el avance del comercio. Tampoco han llegado a la actualidad demasiadas evidencias físicas de piezas de mobiliario. Los antecedentes, por lo tanto, se buscan en inventarios, pinturas o manuscritos.

Algunas tipologías de este periodo son la cama con dosel en los ámbitos residenciales y en el ámbito eclesiástico, los escriptorium, las sillerías de coro, "en especial constituían el medio en que se mostraba la maestría de los entalladores medievales" (Lucie-Smith, 1980, p. 51). En el siglo XVI, los inventarios dan información sobre mobiliario de madera y la menor importancia que este tiene frente a las ropas de cama y los tejidos. Se evidencia un cambio en los gustos cimentado en la invención de la imprenta y la técnica del grabado. Esto influye en los mueblistas en materia de estilos por la difusión de las teorías que servían de base al neoclasicismo, que a su vez desarrollarán una nueva gramática de la ornamentación. En el norte de Europa, se evidencian algunas alteraciones en la ejecución del mueble con cambios en la organización del trabajo y su consolidación en el sistema gremial. Un nuevo detalle constructivo significativo fue realizar el mueble con pequeños paneles montados en armazones y montantes. Este tipo de ensamble los hizo más livianos y transportables, a la vez que permitía a la madera trabajar (expandirse y contraerse) en climas húmedos. Aquí se da un cambio trascendente y que se consolida con el gremio de los ensambladores, que impusieron sus procedimientos en la construcción de muebles y en los conflictos entre distintos gremios. A su vez, se dividieron las tareas entre los gremios con más énfasis. "Pese a esta rígida estructuración, había una gran movilidad entre los artesanos, lo que supuso una atenuación de las fronteras estilísticas. Eran frecuentes los cambios de residencia por razones económicas y, en ocasiones, por conflictos políticos o económicos" (Lucie-Smith, 1980, p. 56).

Estas migraciones ayudaron a difundir las novedades técnicas que influyeron en las pautas estéticas y funcionales del mobiliario. Las causas de estas migraciones no fueron solo económicas o políticas sino también, religiosas:

La creciente prosperidad de Ámsterdam y su importancia como refugio de protestantes queda acreditada por el hecho de que entre 1500 y 1600 se incorporaron a su gremio de trabajadores de la madera no menos de 59 constructores de armarios y afines y 12 constructores de sillas y asientos. Muchos eran emigrantes de otras zonas de los Países Bajos (Lucie-Smith, 1980, p. 57).

Esta circunstancia se complementa con la difusión de teorías y rasgos ornamentales mencionados anteriormente que provocan mejoras en la producción del mueble. Por lo tanto, la consolidación de técnicas constructivas está muy relacionada con las migraciones de carpinteros pertenecientes a distintos gremios, que son a su vez, el medio de difusión de estas técnicas. Asimismo, estos avances permiten mejoras estructurales que incorporan otras mejoras vinculadas a terminaciones superficiales. 
Estos migrantes introdujeron técnicas y formas de construcción no aprobadas por los gremios locales. A finales del siglo XVI, en Inglaterra los extranjeros sobre todo flamencos generalizaron la construcción a base de tableros en lugar del sistema de paneles montados en un armazón. La nueva técnica de ensambladura en cola de milano para unir las tablas de manera que se lograse una pieza solida de anchura deseada, supuso una gran mejora sobre la construcción medieval con tableros (Lucie-Smith, 1980, p. 57).

Estas mejoras, en términos técnicos, dieron lugar a la evolución de nuevos avances en las terminaciones superficiales como el enchapado o el empleo de marquetería muy trabajada. El estilo clásico se evidencia primero en el ámbito eclesiástico, debido a que eran los arquitectos los que amueblaban los interiores de sus obras. En el ámbito doméstico, aparece en Italia una tipología típica de este periodo, la cassapanca, una combinación de asiento y arcón, o el cassoni o cassone, que es un arcón con una decoración más profusa. Muchos trabajados con tallas o paneles pintados o con la técnica denominada pastiglia (una especie de relieve aplastado dorado y, a veces, pintado) y la intarsia o taracea.

El dominio político a través de invasiones, también generó influencias estilísticas:

El mobiliario y los modos decorativos italianos influyeron enormemente en Francia y España, si bien también se produjo una influencia recíproca desde la península Ibérica, desde el momento en que Italia empezó a caer bajo el dominio de los Habsburgo, tras la batalla de Pavía (1525) (Lucie-Smith, 1980, p. 60).

Por su parte, en Francia:

(...) los estilos renacentistas italianos entraron en tiempos de Carlos VIII y Francisco I, como resultado de las invasiones de Italia por los franceses. Artesanos italianos, que llevaban, además de estilos de mobiliario, ideas de decoración para los nuevos palacios, se instalaron en seguida en Amboise y Fontainebleau (Lucie-Smith, 1980, p. 62).

En cambio, en España las ideas del renacimiento se aceptaron con cierta renuencia, debido a la fuerte influencia musulmana.

Otra de las razones fue el desarrollo económico de algunas ciudades como el caso de Alemania y Flandes donde se van gestando nuevas corrientes estilísticas, a pesar de su fragmentación política y conflictos religiosos. Esta región se convierte en el centro económico europeo de esa época, con el consecuente aumento de la población y el establecimiento de corporaciones y gremios artesanos poderosos.

Cabe mencionar también el caso de Inglaterra que en el reinado de Enrique VIII, las ideas renacentistas llegan fielmente pero a un ámbito cortesano muy limitado, a aristócratas e intelectuales. "(...) a mediados del siglo XVI, Enrique VIII fue el precursor de la contratación de artesanos extranjeros (...)” (Yates, King y Bridge, 1999, p. 18).

Aquí se da una influencia del estilo clásico, pero que los artesanos utilizaban de modo más rudimentario, empleando partes sujetas a las pautas estilísticas y otras formas más rústicas 
o de uso técnico-formal del lugar. Esta forma propia de interpretación de cada región de los estilos importados, se da en otros países europeos incluso en América, quizás por gusto, búsqueda de diferenciación, falta de oficio o dificultad constructiva.

Uno de los temas decorativos predilectos era una cabeza pseudoclásica tallada en un tablero, ornamento de un mueble que en lo demás era "vernáculo". Estos tableros esculpidos se denominan en las obras de la época labor romayne (Lucie-Smith, 1980, p. 65).

Se desarrollan mejoras en términos constructivos y de confort con la incorporación paulatina de la tapicería en asientos y la reducción del tamaño y peso de algunos muebles. Algunas tipologías que se suman son la cómoda en Italia en la última década del siglo XVI y las mesas, que se ejecutan en mayores dimensiones para comer ya que los comensales no se ubican en un solo lado sino a ambos lados, como rasgo relevante y reflejo de la evolución y cambios sociales.

Asimismo, el auge económico y el comercio creciente de objetos provoca un cambio en el consumo de mobiliario como rasgo de migración y diseño, con la búsqueda de muebles exóticos. En Holanda, por ejemplo, fueron reemplazados los muebles más sólidos del siglo anterior por piezas exóticas traídas por los traficantes holandeses desde la India, con laqueados e incrustaciones de ébano y carey. Estos estaban realizados con técnicas aún no desarrolladas que van a influenciar en el gusto y en la búsqueda, por parte de los realizadores, en lograr esos efectos decorativos. La técnica del laqueado japonés y de la India influenció al mueble europeo: "Surgieron en seguida imitaciones europeas inspiradas en las arcas y los armarios laqueados importados de la India y otros lugares situados más hacia el este" (Lucie-Smith, 1980, p. 73).

Del mismo modo, son los artesanos indios que habían sido adiestrados por los colonos holandeses, portugueses e ingleses en la fabricación de mobiliario, quienes realizan piezas con formas europeas y ejemplares de producción propia. Un ejemplo son las sillas de junco que fueron imitadas por fabricantes europeos adaptándolas al gusto de sus clientes. Como tipología de este periodo se destaca el armario y el espejo y cabe mencionar que debido al creciente comercio se evidencia la incorporación de maderas exóticas, en especial, el ébano. El armario implicaba nuevos desafíos técnicos constructivos y capacidades artesanales. Los primeros especialistas en estos trabajos fueron llamados maitres ebanistes en París en 1638. Otro caso de migración y diseño de relevancia se puede ver con la incorporación de artesanos especialistas italianos, convocados a los talleres reales franceses, para transferir conocimientos estético-técnicos que sirvieron de base para crear un estilo propio. En Francia, en tiempos de Luis XIV y con la influencia del cardenal Mazzarino, el coleccionista de muebles italiano que disfrutó del poder supremo en Francia, se funda un taller donde se producían los muebles para el rey, que en 1667 se eleva a rango de Manufacture Royale des Muebles de la Couronne. Sumado a otro taller el Garde-Mueble real, comienzan a fabricar muebles, primero siguiendo la tendencia italiana, para lo cual convocaron a especialistas italianos que formaron a los ebanistas franceses, y que luego a lo largo del tiempo fueron consolidando un estilo propio.

Según Yates, King y Bridge, 1999, p. 34-35): 
Entre Inglaterra y el resto de Europa se produjo un importante cruce de ideas a través de la persecución religiosa de los hugonotes, protestantes franceses, emprendida por la Iglesia Católica. Guillermo y María (llegados a Inglaterra desde Holanda para tomar posesión del trono, en 1689) invitaron a refugiarse en Inglaterra a los acosados hugonotes, muchos de los cuales eran expertos artesanos. (...) uno de los cuales fue el célebre Daniel Marot.

Muchas de las exportaciones inglesas del periodo neoclasicista, se dirigían a sus colonias norteamericanas, gran parte a las ricas colonias sureñas. En cambio, las colonias del norte contaban con manufacturas propias y así surgen la primera industria del mueble americana independiente. "Aunque basada en prototipos ingleses, creó algunas formas locales reconocibles como el escritorio labrado al frente" (Lucie-Smith, 1980, p. 114). Inglaterra exportaba también maestría profesional, ya que muchos artesanos extranjeros viajaban allí para completar o perfeccionar su aprendizaje, siendo en estos casos migraciones con fines profesionales. Se destaca la labor de Abraham Roentgen, fundador de la industria Neuwied en Alemania, quien se formó en Londres; y, el principal mueblista sueco de finales del siglo dieciocho, Georg Haupt (Lucie-Smith, 1980, p. 115).

Entre los principales ebanistas ingleses, se destaca la figura de Thomas Chippendale, quien produjo el catálogo de muestras bajo el título de Gentleman and Cabinet-Maker's Director, en 1754. Esta edición permitió que su fama se extendiera por Europa y el mundo. También, se destacan William Kent, el arquitecto escocés Robert Adam y George Hepplewhite. Este último realizó un catálogo de extensa consulta mundial, en 1788: The Cabinet-Maker and Uppholsterer's Guide (Yates, King y Bridge, 1999, p. 66).

También en Francia, el estilo Imperio logró gran difusión a través de publicaciones de sus más importantes creadores, Charles Percier y Pierre-Francois-Léonard Fontaine, con Recueil des décorations intérieures, publicado en 1801 y con las exhibiciones en el patio del Louvre en 1802 y en la explanada de los inválidos en 1806.

\section{Estados Unidos}

Según Yates, King y Bridge:

En los muebles fabricados en América a lo largo del siglo XVII quedaban reflejados los gustos y los estilos de la madre patria de los colonos. (...) se filtraron diseños procedentes de Europa, especialmente de Inglaterra, pero los diseños coloniales americanos siguieron conservando gran parte de su propio carácter, siendo mucho más sencillos y funcionales que sus congéneres europeos (1999, p. 35).

Muchas de las exportaciones inglesas del periodo neoclasicista, se dirigían a sus colonias norteamericanas, especialmente, a las ricas colonias sureñas. En cambio, en las colonias del norte contaban con manufacturas propias, surgiendo la primera industria del mueble 
americana independiente: "Aunque basada en prototipos ingleses, creó algunas formas locales reconocibles como el escritorio labrado al frente" (Lucie-Smith, 1980, p. 114).

El estilo Imperio llega a Estados Unidos, fundiéndose con influencias del Regencia inglés, con exponentes como el ebanista neoyorquino Duncan Phyfe. Aquí se evidencia otra migración vinculada al diseño, ya que los ebanistas norteamericanos debían competir con los que migraban hacia América del Norte, tras la Revolución Francesa. "Uno de esos emigrantes era Honore Lannuier, llegado a Nueva York en 1803. Sus muebles solían tener armazones metálicas al modo francés, siendo por lo general más trabajados que los de Phyfe" (Lucie-Smith, 1980, p. 123).

\section{América colonial}

Las sucesivas colonizaciones acontecidas en América introducirán los diversos estilos europeos según la región de la cual proviniera el conquistador. En referencia a los estilos que llegan de Europa, se destacan el Renacimiento, el Manierismo, el Barroco, el Rococó y el Neoclasicismo. Estos estilos se irán amalgamando con los lenguajes ornamentales y materiales propios de la zona ocupada, creando nuevos lenguajes estilísticos. Fueron parte de las corrientes migratorias artistas, arquitectos, maestros carpinteros, doradores, estofadores, ensambladores, entalladores y artesanos, provenientes de España, que trajeron su experiencia para la formación y dirección de talleres para construir mobiliario para el ámbito eclesiástico y civil.

Este tipo de migraciones se evidencian, por ejemplo, con la llegada de algunos personajes puntuales, como menciona Campos Carlés de Peña: "Bernardo Bitti (1548-1610), nació en Camerino, Italia. Fue un sacerdote jesuita que arribó al Perú en 1575, con el objetivo de 'evangelizar por medio del arte"” (2013, p. 30) y “Juan Martínez Montañés (1568-1649), fue un famoso escultor, imaginero y maestro ensamblador de retablos de origen sevillano, que se manifestó tanto en el estilo renacentista como en el manierista y el Barroco" (2013, p. 33). Otra oleada migratoria estuvo conformada por los esclavos de origen africano, que se sumaron a trabajar de manera forzada, junto a la población autóctona, en obras arquitectónicas.

Cabe destacar también la presencia de artesanos de origen árabe, con su aporte del arte hispano-musulmán, que inspiró al arte mudéjar, especializados en carpintería, metalurgia y ebanistería. La influencia mudéjar es evidente en gran parte del mobiliario, especialmente en el cuero trabajado, que se lo conoce como guadamecil con la adopción de la vaqueta o cordobán repujado para tapizar o revestir muebles de asiento y confeccionar contenedores como maletas y petacas. A través de las crónicas del Paraguay, se sabe que los cordobanes realizados en cuero de cabrito o venado se llamaban así en alusión a la artesanía proveniente de Córdoba, que fue la capital del Sultanato en España.

Por otro lado, artistas y artesanos de Alemania e Italia llegaron a principios del siglo XVII, donde la estampa flamenca, alemana e italiana se perciben en los muebles decorados con placas de marfil o hueso pirograbados recreando escenas bíblicas, sobre fondos de carey o caoba. 
El Virreinato del Perú, que comprende los actuales territorios de Perú, parte de Ecuador, el oeste de Bolivia, el norte de Chile y de Argentina, se fundó en 1542, con la ciudad de los Reyes, como su capital del Virreinato. Otras dos ciudades que adquirieron gran relevancia fueron Lima y Cusco, siendo esta última una versión americana de una típica ciudad española. Construida sobre cimientos incas, tuvo grandiosas expresiones artísticas tanto en la esfera civil como religiosa, resultado de la fusión de dos culturas. La arquitectura de ciudades como Trujillo y Arequipa se destaca por su originalidad y belleza, resultado también del mestizaje de dos culturas, en donde se evidencia el lenguaje barroco europeo en los escudos heráldicos, religiosos y civiles y en utilización de la piedra de sillar en fachadas, decoradas mediante la talla plana, pero con motivos autóctonos, como la mazorca del maíz y la Kantuta.

Asimismo, la catequización realizada por la Orden Dominicana y la Compañía de Jesús, entre otras, trajo aparejada construcciones fuertemente influenciadas por las tradiciones arquitectónicas de origen europeo pero con tallas planas esculpidas en piedra con motivos vernáculos oriundos de la selva amazónica como conchas, sirenas, loros, monos y piñas. Para acompañar este desarrollo arquitectónico, se produjeron gran cantidad de muebles eclesiásticos y civiles, dotados de gran expresividad y carga simbólica. Algunas tipologías, dentro de los ámbitos eclesiásticos fueron: trabajos en columnas y retablos, adosados a los muros, como la sillería de coro alta y baja o los pulpitos, cancelas, ambones, muebles de sacristía y cátedras. Entre los móviles, se encontraban, entre otros, el órgano portátil, el banco, el escaño, el altar portátil, la sacra y el atril de pie.

En lo referente al ámbito civil, las tipologías más utilizadas fueron el bargueño, el arcón, la arqueta, el armario, el sillón misional, el escaño o asiento múltiple, la cama, la cuna, la cómoda y el escritorio. Los muebles contenedores llegaron de España durante el siglo XVI. Este mobiliario inspiró a artesanos, maestros entalladores y doradores autóctonos que, adecuadamente adiestrados, fueron capaces de construir ejemplares tales como, arcones, bargueños, armarios y camas con altos baldaquinos. El material más utilizado era la madera de cedro, caoba, sauce y aliso. El tratamiento superficial era con panes de oro, lacas de origen oriental o la autóctona, llamada barniz de pasto. Junto con policromías, trabajos con carey y conchaperla, cuero y marfil.

Se destacó también la fabricación de herramientas con la idoneidad en el trabajo de los metales, tales como el serrucho, la gubia, el formón, el martillo, el hacha, la tijera, y la aguja, realizados en hierro. Oficios relacionados a estas herramientas, como la carpintería y la platería, encontraron indígenas entrenados que lograron igualar la producción calificada de ciertas áreas de la península. De este modo, se logró una producción de marcadas tradiciones criollas. Este fértil intercambio vio nacer estilos de mobiliario auténticamente americanos.

Como puntal de la educación y la cultura, la primera imprenta se estableció en Lima en 1581, con la publicación del primer libro sobre la doctrina cristiana y el catecismo, escrito en tres idiomas: español, quechua y aimará. A su vez, se realizaron ediciones de grandes arquitectos y artistas, como Andrea Palladio, atesorados en conventos en poder de arquitectos y maestros de obra.

Por su parte, las universidades, donde se difundió el conocimiento, fueron el destino de la migración de muchos profesores y artistas. Algunas de ellas son: San Marcos de Lima, la 
más antigua de América fundada en 1551, San Antonio de Abad del Cusco, Chuquisaca en Alto Perú (actual Bolivia), Universidad de Córdoba (actual Argentina), San Cristóbal de Huamanga, Gran Padre San Agustín de Arequipa y Santiago de Chile, entre otras. Enseñaron música y oficios e impartieron la doctrina del cristianismo.

De todos modos, a partir del siglo XVII, se abandonó casi completamente la impronta europeizante tanto en la pintura como en las artes aplicadas, que incluía al mobiliario. Se manifestó una creativa superposición de elementos del imaginario aborigen de gran carga simbólica, exotismo y sabor local.

Surgió así un tipo de arte renovado que adoptó un lenguaje estético mestizo propio del mundo sur andino y evolucionó en todas sus formas expresivas. Su calidad artística perduró a lo largo del siglo XVIII a base de autonomía en las decisiones por parte de artesanos vernáculos. Esta tendencia abarcó una extensa zona comprendida por Arequipa y las Tierras Altas, que incluían Cusco hasta la ribera del lago Titicaca y el camino al Potosí, llegando a la actual Bolivia. Su cronología se mantuvo independiente de la europea, nació de su propia realidad (Campos Carlés de Peña, 2013, p. 19 y 20).

El arte barroco andino o mestizo se originó en el Virreinato del Perú a partir del último cuarto de siglo XVII hasta lograr su esplendor en el siglo XVIII. Algunos de los rasgos distintivos de este estilo son la talla planimétrica en contraposición con la talla de medio punto, la frontalidad y la utilización del color. Iconografía nativa como frutos de la tierra en comunión con elementos del lenguaje universal, aplicados no solo en mobiliario sino también en textiles, vajilla de metal y cerámicas. Todos estos elementos disimulados entre elementos permitidos. Como expresa Campos Carlés de Peña:

Demanda especial atención ciertos detalles por ser eficientes vehículos de expresividad, como personajes masculinos y femeninos aborígenes danzando, figuras aladas de mujer, a menudo grávidas, niño cargador en forma de ménsula, rostros de facciones nativas representando querubines alados, figuras fantásticas del hombre verde o barbado, de frente o de perfil, que emerge de entre la hojarasca; sirenas con importantes colas escamadas o de follaje, tocadas con coronas de flores o plumas rasgueando el charango, la guitarra o el laúd (2013, p. 40).

Se presentan otros elementos que menciona la autora, para expresar esta evidencia en el mundo objetual del Barroco Andino, que en su mestizaje logra un lenguaje propio. Algunos de estos elementos son: la sirena que simboliza la belleza femenina, la vanidad y la inconstancia, la Kantuta (flor sagrada de los incas), que se utilizó como elemento decorativo y el puma (felino americano), como símbolo de bienvenida. La serpiente (que alude al mundo de los muertos), el cuy, la vizcacha, los monos comiendo uvas, considerado por muchos pueblos amerindios augurio de buenas noticias y protector de la salud, el perro sin pelo peruano (viringo, mascota de los incas), el colibrí, apreciado porque tenía la capacidad de volar para atrás, y extraer néctar de las flores, considerado como una deidad. 
Algunos frutos, se ven en guirnaldas, coronas o canastos, como la granada, la papaya, la mazorca, la vid, el girasol y la piña. Como explica Campo Carlés de Peña refiriéndose a esta particularidad estilística a raíz de la mezcla de estas culturas y su simbología mística:

En la cosmovisión inca, Inti, era el dios Sol, a quien adoraban y del que descendían sus gobernantes, y Mama Killa o Quilla, la diosa Luna de la fertilidad; eran hermanos y esposos. Esta dualidad se replantaba mediante el uso del oro -sudor del sol- y la plata -lágrimas de la Luna-. Fueron estos símbolos vernáculos muy usados por artesanos indígenas en la ornamentación del mobiliario barroco mestizo (2013, p. 44).

Posteriormente, Inglaterra introduce en puertos del Virreinato de Nueva España mobiliario estilo Reina Ana y luego estilo Chippendale, que llegaron a las costas del Perú, en el primer tercio del siglo XVIII. Luego con el estilo rococó, que se aleja de los temas religiosos, le da cierta libertad a los artistas, en su producción. Finalizando con el estilo neoclásico que se adoptó pero con rasgos más simplificados. Por otro lado, se evidencian influencias orientales por vías del intercambio comercial o por migraciones. Por ejemplo, en México, a partir de 1565, se logró establecer una vía comercial directa con China, a través de la navegación regular entre Manila y Acapulco, absorbiendo una fuerte influencia oriental mayor que cualquier otro virreinato posterior y desarrollando artesanías propias a partir de aquellos modelos (Bomchil y Carreño, 2011, p. 50). Una tipología de asiento de origen oriental es la silla con esquema en $\mathrm{X}$, con funciones complementarias como plegado lo que le permite ser transportable al reducir su volumen, y mantuvo su condición de asiento prestigioso en el Nuevo Mundo, como describe Bomchil y Carreño:

En ese documento tan precioso sobre la conquista de Méjico que es el lienzo o tapiz de Tlaxcalla, una y otra vez reconocemos al gran jefe español por estar sentado como en un trono sobre la silla mora con la princesa maya, Malintzin, de pie, a su lado oficiando de intérprete (2011, p. 59).

En el tratamiento superficial con lacas, la Escuela kano, fue una famosa dinastía de artesanos. Kano Domi, quien fue uno de estos artesanos, estuvo en Manila en 1603, luego viajó a México donde colaboró con la dinastía González, también especialista en esta materia. "Esta fue una familia de artesanos japoneses cristianizados, quienes siguieron esta técnica tradicional, a la que Tomás González Villaverde y su hijo, Miguel, sumaron la técnica del enconchado sobre madera" (Campos Carlés de Peña. 2013, p. 19). De esta decoración oriental, especialidad de origen filipino, existen dos tipos, la taracea o incrustación, de pequeños trozos de nácar sobre la superficie de un mueble, o el enconchado que resulta del laminado de este material, que se coloca de forma superpuesta sobre la superficie del mueble.

Otra tipología son los palenquines, que eran lechos portátiles, o las bocetas que eran cajitas cilíndricas con tapas labradas, que se utilizaban para enviar medicamentos a los monjes, "Una versión cristiana de los tradicionales begging bowls -boles para limosna- de los monjes budistas" (Bomchil y Carreño, 2011, p. 61). 
En el caso del Virreinato del Perú, recibió influencia oriental debido a su salida directa al pacifico, "se encuentran evidencias de migración proveniente de Japón hacia las costas del Perú que se remontan al siglo XVII, en algunos casos procedentes de Filipinas. Unos pocos pobladores de origen japonés vivieron en Lima a partir de 1607" (Campos Carlés de Peña, 2013, p. 19). Una tipología que evidencia este hecho es el estrado, que es una elevación aplicada a un mueble, o como extensión de la arquitectura utilizado en los interiores civiles coloniales americanos, siendo esta forma de reposo muy común en todo Oriente. Esta modalidad de estar más recostado que sentado, que se da en la India y en los países orientales, no es privativo de las mujeres, hecho que distingue al estrado en España, pero no para todas las mujeres, ya que esta elevación será un rasgo de nobleza hispánica, tipología y costumbre que también los conquistadores llevarán al Nuevo Mundo.

En cuanto al Virreinato del Río de la Plata, debido a trabas que experimentó el puerto de Buenos Aires, el conquistador contaba con pocos muebles, al comienzo de la conquista. Muy pocas casonas contaban con mobiliario como; el estrado, el sofá, sillones, sillas, mesa angosta con bancos laterales, la alacena, las cujas o camas con patas en forma de tijera tipo catre, el arcón que evoluciona en la cómoda más tarde. El escritorio, la cómoda papelera o mueble contador y un oratorio. Por otro lado, como menciona Pampolla: "en el rancho pobre, apenas un catre con tientos de cuero crudo, la cuna, que generalmente se hallaba colgada de tientos, un barril con agua, un chifle y algún asiento de cabeza de vaca" (1948, p. 5). Recién a partir del siglo VIII se pueden encontrar casas amuebladas con la llegada de algunas familias que se instalan a vivir. Algunas de las maderas utilizadas son el quebracho, el cedro de Misiones, el petiribí, el cedro de Salta, el jacarandá de Córdoba y Salta, la tipa colorada y el nogal entre otras. Destaca Pampolla sobre el trabajo del aborigen:

El aborigen cumplirá su obra en una doble faz, aprendiendo su oficio e imprimiendo su sello al objeto que trabaja, como es dado observar en las gesticulaciones duras y agudos perfiles de muchas imágenes que puebla el suelo americano, o en el empleo de motivos zoomorfos y fitomorfos autóctonos (1948, p. 5).

En estas casas de los aborígenes surge un mobiliario rústico, básico y eficiente, muy relacionado con la naturaleza y los medios que ella le proporciona. Un ejemplo posible es la provincia de Santiago del Estero donde se han registrado algunas piezas que son testigos de estos pobladores y su arte. La fundación de Santiago del Estero fue uno de los hechos más importantes de la colonización española en América, siendo el primer asentamiento poblacional de Argentina. En esta zona del norte argentino se da una particularidad vinculada a las migraciones anteriores a la conquista, donde se produce un mestizaje producto de la llegada a una zona fértil de la Mesopotamia, de muchos pueblos. Como destacan Carballo y Paz:

Hace varias generaciones que los habitantes del monte no son indios sino criollos, pero desde siempre el monte fue mestizo y un lugar de encuentro de muchos pueblos andinos. Muchos siglos antes de la llegada del hombre blanco ya convivían en el pueblos de los más diversos orígenes, atraídos por la fértil Mesopotamia formada entre los ríos Dulce y Salado (1998, p. 20). 
Sobre la producción de mobiliario y objetos del monte, con sus primeros hombres frente a la naturaleza, descubriendo la forma de resolver sus necesidades con lo que el monte les proveía, los autores amplían:

Nada sobra en la sencillez de sus casas. Allí, como en la naturaleza, todo tiene sentido. Es esta misma lógica de lo elemental, de lo estrictamente funcional, la encontramos en sus muebles. La pureza de líneas que tanto se empeña en conseguir el diseño moderno aparece inocentemente resuelta en estas piezas que nos sorprenden con la simpleza de lo necesario y la sobriedad de lo imprescindible. Como si este modo de ver y usar la naturaleza fuese el eslabón perdido en el mundo del diseño. ¿No habrán nacido así, en todas partes, los primeros muebles de los primeros hombres? (Carballo y Paz, 1998, p. 11).

El mobiliario de estas casas de adobe es escaso, y mucha de la vida cotidiana se da más afuera que adentro de la casa. Un mobiliario utilitario con tipologías básicas, que trasciende su tiempo, realizado por artesanos y no por grandes ebanistas, que no son influenciados por los estilos de su época, como menciona Lucie-Smith sobre el mobiliario del siglo XVII en Europa, del que pocas publicaciones hablan:

(...) existía una gran producción de muebles corrientes, utilitarios. En este terreno, el siglo XVII vio surgir algunos tipos básicos, que habían de gozar larguísima vida (...) Por lo prácticos y útiles que eran, algunos muebles empezaron a adquirir en este periodo la forma que conservarían durante muchos años. Diestros y sencillos artesanos rurales por lo común 'ensambladores`y no ebanistas repitieron una y otra vez los mismos diseños, sin apenas cambiarlos (...) Muchos muebles se vieron así libres de influencias de la moda y, siquiera de manera inconsciente respondían únicamente al principio de la idoneidad para un uso concreto (1980, pp. 89-91).

La arquitectura vernácula da respuesta eficiente a los condicionantes climáticos propios de su región. Esta eficiencia propia del que interpreta con inteligencia su medio, sin la necesidad de hacer referencia a su intérprete, lo que Norberto Chaves define como diseño invisible, un diseño eficiente que ya no le pertenece al autor sino al público:

El artesano revela su oficio cuando acaba la obra sin dejar huellas. O mejor aún; la obra, que es su huella, cobra valor por sí misma y deviene universal y, con ello, transforma en universal la mano que en ella se revela (2005, p. 57).

Este mobiliario anónimo pero representativo para la persona que lo hizo con sus propias manos, quizás para sí, cuando la familia se agranda o como un encargo de algún vecino, o para un pariente o como un regalo, representan el monte, y un recuerdo de su origen.

La inteligencia aplicada al diseño se manifiesta en la sabiduría con la que se administraron los recursos, utilizando siempre al menor cantidad de materia 
prima posible sin renunciar a la calidad constructiva, la solidez y funcionalidad. Es esta simpleza la que otorga a estos muebles un carácter propio e inconfundible (Carballo y Paz, 2011, p. 23).

Algunos materiales utilizados en la arquitectura y el mobiliario son: maderas, quebracho blanco y colorado, el itin que se utiliza para hacer horcones, para carpintería el chañar y el algarrobo y el huiñaj. Otras maderas son el anoche, y el garabato, el cardón, y para yerberas, casitas de santo que son más livianas, se usa la punua. Las herramientas para su ejecución son la azuela, el cuchillo y el hacha. Posteriormente, se suman el taladro y el serrucho, entre otros.

Sobre la migración producida por la colonización de estas poblaciones que, como se mencionó, ya contaban con un mestizaje propio, se destaca la llegada de los españoles, que se produjo por variables económicas, políticas, religiosas. Carballo y Paz mencionan que:

Los españoles trajeron en su sangre y su cultura la impronta de siete siglos de dominación islámica. Es difícil sostener que no hubiese moros entre aquellos valientes. Aprovechar la norma islámica que permite a un musulmán amenazado de muerte ocultar su religión fue, para muchos de ellos, un modo eficaz de eludir las políticas de intolerancia religiosa. Moros y judíos que no aceptaban la opción de convertirse al cristianismo o retornar al norte de África se embarcaban en la aventura del nuevo mundo; proporcionaban así mano de obra calificada a los adelantados (...) (1998, p. 20).

Por otro lado, el textil es un antecedente de migración que se expresa en su configuración material, técnica y formal o decorativa, evolucionando desde sus primeras expresiones con motivos de origen andino, a las configuraciones influenciadas por la llegada de los españoles e ingleses. El monte de Santiago del Estero registra referencias de origen prehispánico del tejido, en tradición oral de leyendas que aportan datos complementarios al origen incaico del arte textil, como también la expansión de este con la organización de los españoles como explica Ana María Llamazares y Carlos Martínez Sarasola en el trabajo de Carballo y Paz:

Hacia fines del siglo XVI, los obrajes textiles organizados por el obispo Vitoria alcanzaron tal magnitud que dieron lugar a la primera exportación de que se tenga memoria en lo que es hoy la Argentina: el 2 de septiembre de 1586 un cargamento de textiles santiagueños en Buenos Aires, para desde allí ser embarcado con destino a Brasil. Los textiles fueron vendidos en ochenta mil ducados, una cifra muy importante para la época, y la fecha quedo incorporada al calendario como "Día de la Industria” (1998, p. 90). 


\section{Conclusiones}

Como se evidencia en el presente artículo, los antecedentes que conforman los inicios del canon en Occidente estarán fuertemente influidos por el Cercano y Lejano Oriente, desde la Antigüedad en adelante. A partir de la conquista del continente americano, Europa trasladará muchas de estas influencias al nuevo mundo, tomando a su vez elementos propios del nuevo continente. Esa nueva amalgama de estilos colonizadores y vernáculos ampliarán aún más dicho canon. Estas son claras evidencias de la importancia de las migraciones en el ámbito del diseño de mobiliario.

Como expresa Chaves sobre esta tradición objetual producto de estas migraciones:

Memoria incierta y ensoñación: algo así nos ocurre con estos objetos. Formas naturalizadas como las palabras, que componen un léxico lejano aprendido antes de la amnesia. Como los arcanos, siempre presentes, estas sillas, estas mesas, estas camas nos recuerdan algo propio largamente olvidado. Y reconocerlas es como acordarse de uno mismo. Unas formas incorporadas no solo por la mirada, sino por una experiencia múltiple: el uso, el tacto, el olfato... Se comprenden pues han sido aprendidas muy temprano, tal como fue aprendida la madera: su textura, su olor, su peso. Incorporadas a nuestros reflejos, forman parte, también de nuestra biografía (en Carballo y Paz, 2011, p. 19).

\section{Bibliografía}

Bomchil, S. y Carreño, V. (2011). El mueble colonial de las américas y su circunstancia histórica. Buenos Aires: Editorial Sudamericana.

Campos Carlés de Peña, M. (2013). Un legado que pervive en Hispanoamérica. El mobiliario del Virreinato del Perú de los siglos XVII y XVIII. Madrid: Ediciones El Viso.

Carballo, B. y Paz, R. (comp.) (2011). Monte. Ciudad de Buenos Aires: Ediciones Arte Étnico Argentino.

\section{Étnico Argentino.}

. (2006). Teleras. Memoria del monte quichua. Buenos Aires: Ediciones Arte

. (1999). Un arte escondido. Objetos del monte argentino. Buenos Aires: Ediciones de Arte Gaglianone.

Chaves, N. (2005). El diseño invisible: siete lecciones sobre la intervención culta en el hábitat humano. Buenos Aires: Piadós.

Instituto Nacional de Estadísticas y Censo INDEC. Encuesta complementaria de migraciones internacionales (ECMI). Disponible en https://www.indec.gob.ar/micro_sitios/ webcenso/ECMI/ecmi_metodologia_web.pdf

Lucie-Smith, E. (1980). Breve historia del mueble. Barcelona: Ediciones del serbal.

Organización Internacional para las Migraciones OIM. Disponible en: https://www.iom. int/es

Pappolla, R. (s/f). El mueble en América del Sur. Buenos Aires: Ediciones Centurión. 
UNESCO. Disponible en: https://en.unesco.org/

Yates, S.; King, C. y Bridge, M. (1999). Enciclopedia del mueble. Madrid: Editorial Libsa.

\begin{abstract}
From the beginning of the history of design, a varied universe of materials, techniques and technologies will delineate an object repertoire. The influences, from Antiquity to the Modern Age, will form a network of migratory movements, motivated by economic interests in some cases, or as a consequence of the political, social and cultural context, in others. The present work will take a tour of these migrations and will study their influence on the formation and expansion of the canon in the West, on many occasions, with strong Eastern influence.
\end{abstract}

Keywords: history - Antiquity - Middle Ages - Modern Age - West - East - migration design - furniture.

Resumo: Desde o início da história do design, um universo variado de materiais, técnicas e tecnologias delineará um repertório de objetos. As influências, da Antiguidade à Idade Moderna, formarão uma rede de movimentos migratórios, motivados por interesses econômicos em alguns casos, ou como consequiência do contexto político, social e cultural, em outros. O presente trabalho fará um tour dessas migrações e estudará sua influência na formação e expansão do cânone no Ocidente, em muitas ocasiões, com forte influência oriental.

Palavras chave: história - Antiguidade - Idade Média - Idade Moderna - Ocidente - Oriente - migração - design - móveis.

[Las traducciones de los abstracts fueron supervisadas por el autor de cada artículo] 